\title{
Radial artery conduits for coronary artery bypass grafting: Current perspective
}

\author{
Shafi Mussa, MA, MRCS \\ Bikram P. Choudhary, MRCS \\ David P. Taggart, MD(Hons), PhD, FRCS
}

A supplemental list of references is available online. 伊
From the Department of Cardiothoracic Surgery, John Radcliffe Hospital, Oxford, United Kingdom.

Received for publication June 27, 2004; revisions received July 23, 2004; accepted for publication July 28, 2004

Address for reprints: David P. Taggart, MD(Hons), PhD, FRCS, Professor of Cardiovascular Surgery, University of Oxford, and Consultant Cardiothoracic Surgeon, John Radcliffe Hospital, Headington, Oxford OX3 9DU, UK (E-mail: david. taggart@orh.nhs.uk).

J Thorac Cardiovasc Surg 2005;129:250-3

$0022-5223 / \$ 30.00$

Copyright (C) 2005 by The American Association for Thoracic Surgery

doi:10.1016/j.jtcvs.2004.07.040

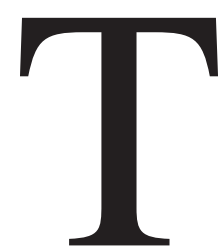

otal arterial revascularization offers the potential to avoid the problems associated with vein graft failure. Bilateral internal thoracic arteries (ITAs) are the conduits of first choice because of excellent short- and long-term patency and the possibility of improved survival. ${ }^{1}$ The radial artery (RA) is easily harvested, versatile, has excellent handling characteristics, and has become the arterial conduit of third choice. ${ }^{2}$ Issues remain concerning its optimal use, however, particularly with reference to preoperative assessment, harvesting techniques, vasospasm prophylaxis, grafting strategy, and long-term patency. This article critically examines the current evidence for these important aspects of RA use.

\section{Preoperative Assessment}

Preoperative assessment of the RA and collateral hand circulation is mandatory to avoid hand ischemia in patients with an inadequate collateral circulation. The most widely used clinical test for assessment of adequate collateral circulation to the hand is the modified Allen test. In our own practice, $85 \%$ of patients have the RA safely harvested after clinical assessment only. ${ }^{3}$ In the remaining $15 \%$ with equivocal or positive Allen tests, further imaging is performed with duplex ultrasonography, which combines pulsed Doppler with a B-mode imager to record vessel flow velocity, vessel caliber and anatomic variations, and severity of atherosclerotic lesions along the entire length of the vessel. Use of bilateral forearm duplex scanning when clinical assessment is equivocal has enabled the use of RA conduits in $99 \%$ of patients scheduled for total arterial coronary artery bypass grafting $(\mathrm{CABG}){ }^{3}$

Concern about the reliability of the Allen test has prompted evaluation of other assessment techniques, such as digital pulse oximetry, digital plethysmography, and Doppler ultrasonographic methods. However, there is no convincing evidence that these result in improved clinical outcomes after RA harvest.

\section{Harvesting Technique}

Improved harvesting techniques are fundamental to the current success of radial grafts in CABG. Further refinements may result in improvements to graft function, reduced complications, and greater patient satisfaction. The options available for RA harvesting are pedicled versus skeletonized, ultrasonic scalpel versus traditional dissection, and open versus endoscopic harvest. Although several studies have compared harvesting techniques, none has been sufficiently robust in methodology or sufficiently powered to detect clinically relevant differences between the techniques, assuming that these exist. A comparison of early angiographic patency of ultrasonic harvested skeletonized versus traditionally harvested pedicled RA conduits demonstrated better patency for skeletonized conduits (97\%) than pedicled conduits $(85 \%)$. Whether these findings reflect the ease of use of skeletonized conduits or the impact of the ultrasonic scalpel, rather than the true effect of skeletonization, remains uncertain. Graft blood flow has been shown to be similar in skeletonized and pedicled conduits, independent of method of harvest. Although significantly greater blood flow has been reported in conduits harvested with 
ultrasonic assistance than with traditional harvest, no difference has been demonstrated in structural or functional endothelial integrity between RA harvested with electrocautery or ultrasonic scalpel.

Requirements for improved aesthetics, accelerated recovery, and greater patient satisfaction have encouraged endoscopic conduit harvesting in CABG. For endoscopic RA harvest, three or fewer 2-cm incisions at the wrist, elbow, and mid forearm are usually all that are required. In contrast, the open technique requires a curvilinear skin incision extending along the length of the forearm. Certainly, endoscopic harvest takes longer than open harvest, carries a similar incidence of dorsal thenar paresthesia, and yields no advantages in terms of wound infection. Despite there being no proven clinical advantage, however, increasing experience and evolving technology is likely to encourage the pursuit of endoscopic techniques. Disadvantages include increased equipment costs and the requirement for specific training.

\section{Vasospasm Prophylaxis}

Vasospasm has been reported in 4\% to $10 \%$ of all RA grafts. This may have potentially significant adverse consequences in terms of perioperative myocardial infarction and low cardiac output syndrome and its sequelae, including extended intensive care stays and increased mortality. Pharmacologic prevention of RA spasm has been fundamental to its revival as a conduit for CABG. Clinically useful agents should ideally be effective against a wide variety of endogenous vasoconstrictor substances liberated because of surgical stress or the inflammatory response to cardiopulmonary bypass, as well as exogenously administered inotropes or vasoconstrictors. Furthermore, antispasmodic activity should ideally be maintained throughout the immediate postoperative period. Finally, the agent should neither cause local injury to the conduit nor have harmful systemic effects. Currently no agents, alone or in combination, can be defined as an ideal antispasmodic, warranting continued development of vasodilator strategies for RA grafts.

Antispasmodic agents can be applied topically or delivered systemically. Topical application of vasodilator agents is convenient and reduces the incidence of the adverse consequences of systemic administration; for example, diltiazem may counteract vasospasm but can precipitate hemodynamic instability through bradycardia, atrioventricular block, and hypotension. Nitroglycerin infusions may be safer and more effective at preventing conduit spasm after CABG than diltiazem but can cause peripheral vasodilatation and are unsuitable for patients with hemodynamic instability. Systemic milrinone may be particularly beneficial in low cardiac output situations, although it frequently causes hypotension, necessitating vasoconstrictor infusions to maintain hemodynamic stability.
Topical pharmacologic preparations in current use fall into three broad categories: phosphodiesterase inhibitors, calcium-channel antagonists, and $\alpha$-adrenergic antagonists. Papaverine, a short-acting phosphodiesterase inhibitor, is a widely used topical vasodilator for arterial conduits. However, in vitro studies demonstrate that the efficacy of papaverine diminishes after 30 minutes. ${ }^{4}$ Thus papaverine may ameliorate spasm during RA harvest but not throughout the intraoperative and immediate postoperative period. Additionally, the preparation is acidic and may damage the endothelium. Milrinone, a longer-acting phosphodiesterase inhibitor found to be a potent vasodilator of RA segments in vitro, has been administered intraluminally to prevent graft spasm with good clinical results. Verapamil and nitroglycerin in combination (VG solution) rapidly and effectively prevents spasm against a wide range of vasoconstrictors, ${ }^{5}$ with improved preservation of endothelial function relative to papaverine. In vitro studies from our group demonstrate that the antispasmodic effect of this combination is largely abolished after 4 hours. ${ }^{4}$

Phenoxybenzamine, a nonselective $\alpha$-adrenoceptor antagonist, prevents catecholamine-mediated RA vasoconstriction, ${ }^{4}$ has a duration of action as long as 18 hours in vitro, and is less harmful to the endothelium than papaverine. However, phenoxybenzamine has no activity against noncatecholamine vasoconstrictors released in response to surgical stress or cardiopulmonary bypass that also may encourage RA vasospasm. ${ }^{4}$ Consequently, in our practice we currently use a solution of phenoxybenzamine $(2 \mathrm{mg} /$ $\mathrm{mL})$ and verapamil $(0.1 \mathrm{mg} / \mathrm{mL})$ in heparinized blood, applied intraluminally and topically to the harvested conduit.

Oral calcium-channel antagonists have been recommended for as long as 1 year after surgery for those patients receiving RA grafts, to prevent delayed vasospasm. In a randomized trial, continuation of diltiazem beyond 1 year in patients with RA grafts provided no additional benefit in terms of clinical and angiographic outcomes.

\section{Grafting Strategy}

Optimal placement of radial artery grafts to achieve satisfactory long-term patency remains controversial. The concept of competitive flow suggests that graft flow is influenced by native coronary flow. Grafted conduits may therefore fare better in conditions of poor native coronary flow, typified by high-grade coronary stenoses. There is accumulating evidence that grafting the RA to coronary targets with moderate stenoses $(<70 \%)$ results in reduced anastomotic patency. ${ }^{6}$

Some studies have reported lower angiographic patency rates for RA grafts to the right coronary artery compared with the left anterior descending coronary artery. ${ }^{6}$ This finding remains controversial, because longer-term studies 
TABLE 1. RA patency for CABG: Summary of published data

\begin{tabular}{|c|c|c|c|c|c|}
\hline Authors & $\begin{array}{l}\text { RA conduits } \\
\text { used }\end{array}$ & $\begin{array}{l}\text { RA conduits } \\
\text { reassessed }\end{array}$ & $\begin{array}{l}\text { Original grafts } \\
\text { reassessed }(\%)\end{array}$ & $\begin{array}{c}\text { Angiographic patency } \\
\text { (FitzGibbon grade A, \%) }\end{array}$ & $\begin{array}{c}\text { Follow-up } \\
\text { (y) }\end{array}$ \\
\hline Acar et al ${ }^{9}$ & 910 & 64 & 7 & 83 & $5.6 \pm 1.1$ \\
\hline Possati et al ${ }^{10}$ & 325 & 62 & 19 & 87 & $4.9 \pm 0.5$ \\
\hline laco et $\mathrm{al}^{11}$ & 164 & $91^{*}$ & 47 & 95 & $4.0 \pm 2.3$ \\
\hline Tatoulis et al $^{12}$ & 8420 & $280(369 *)$ & 3 & 90 & $1.2 \pm 0.9$ \\
\hline Possati et $\mathrm{al}^{7}$ & 91 & 84 & 92 & 88 & $8.8 \pm 0.8$ \\
\hline Khot $^{13}$ & - & 310 & - & 51 & $1.5 \pm 1.4$ \\
\hline
\end{tabular}

*Numbers represent anastomoses reassessed.

have found that target vessel location does not influence graft patency. ${ }^{7}$

Options for the proximal RA anastomosis are most commonly to the aorta as an aortocoronary graft or to another conduit as a composite graft. A comparison of angiographic patency of RA grafts in the aortocoronary versus composite configuration approximately 2 years after surgery demonstrated patency rates of $75 \%$ (aortocoronary) versus $70 \%$ (composite). Proximal anastomosis location did not influence midterm angiographic patency, whereas degree of native vessel stenosis and choice of target vessel did. The pedicled left ITA-RA composite graft has a patency rate of $82 \%$ to $93 \%$ at just under 1 year, comparable to that of aortocoronary grafts.

Composite grafts have the major advantage of facilitating a "no-touch" aortic technique in off-pump revascularization, thereby reducing the risk of embolic debris from the ascending aorta. Potential disadvantages of composite grafts compared with conventional aorta-coronary RA grafts are the relative technical difficulty and the reliance on single inflow (proximal left ITA) to supply all grafted territories.

\section{Midterm and Long-Term Angiographic Patency}

Since the 1990s, several series have demonstrated encouraging midterm and long-term angiographic results of RA grafts. Table 1 details the most pertinent data from each study. Midterm angiographic patency rates vary between $83 \%$ and $95 \%$. Long-term angiographic patency is $88 \%$. $^{7}$ However, the data must be interpreted with caution. All these studies were retrospective analyses, and the percentage of grafts followed up with angiography varies from $3.4 \%$ to $92 \%{ }^{7}$ The quoted patency rates may be based on a relatively small proportion of RA grafts undergoing repeated angiography, usually because of recurrent symptoms, and do not necessarily reflect patency rates for the entire cohort. The assumption that symptom-free patients are likely to have more patent grafts is logical but does not justify extrapolation of graft patency rates. The study by Possati and associates ${ }^{7}$ with $92 \%$ angiographic follow-up to almost 9 years, irrespective of recurrent symptoms, provides the most compelling data to date.
Of considerable interest is the comparative performance of RA versus long saphenous vein conduits. Occlusive disease of vein grafts remains a major limitation of CABG, with as many as $75 \%$ of vein grafts severely stenosed or occluded at 10 years, although refinements in harvesting techniques and the use of aspirin and statins may contribute to improved vein graft performance in contemporary CABG. Most recently, midterm (1.5 years) angiographic follow-up of patients with symptoms after CABG has revealed RA patency rates of $51 \%$, compared with $64 \%$ for vein grafts. The results from this retrospective study are in stark contrast to previous published series but may reflect selection bias because only patients with symptoms underwent repeated angiography.

To address some of these issues, three prospective, randomized, controlled trials comparing RA with other conduits with the intention of complete angiographic follow-up are in progress. The results of the Radial Artery Patency Study (RAPS) and the Radial artery Versus Saphenous vein Patency study (RSVP), are awaited. Recently, the interim (5 year) results of the Radial Artery Patency and Clinical Outcome (RAPCO) study, a prospective, randomized trial comparing RA with saphenous vein grafts and free right ITA grafts, ${ }^{8}$ have been reported. Five-year patency rates between RA and right ITA are 95\% versus $100 \%$, respectively, and those between RA and saphenous vein are $87 \%$ versus $94 \%$, at least according to the small number of patients who have undergone early repeated angiography. No statistically significant differences in graft patency have been demonstrated between RA and other conduits.

\section{Summary and Recommendations}

To optimize use of the RA as a coronary bypass conduit:

- Preoperative assessment is mandatory, and the Allen test is sufficient in most cases. Duplex ultrasonography can be used as an imaging adjunct, and can increase harvest rates toward $100 \%$ where appropriate. ${ }^{3}$

- Several harvesting techniques have been proposed, but data supporting one method relative to another are currently lacking. 
- Application of pharmacologic antispasmodic preparations is vital to prevent perioperative graft vasospasm. Phenoxybenzamine is highly effective against endogenous or exogenous (inotrope-induced) $\alpha$-adrenoceptor-mediated spasm but should be combined with an agent with a broader spectrum of action such as verapamil.

- RA grafts exhibit diminished long-term patency if anastomosed to coronary target vessels with $<70 \%$ proximal stenoses. RA conduits may be used in either an aorta-coronary or composite configuration, with no impact on patency. The choice of which coronary target vessel to bypass with RA grafts remains controversial, with evidence available to support either strategy.

- Ongoing randomized trials will establish the relative long-term patency of RA conduits compared with the more established ITA and long saphenous vein.

\section{References}

1. Taggart DP, D'Amico R, Altman DG. Effect of arterial revascularisation on survival: a systematic review of studies comparing bilateral and single internal mammary arteries. Lancet. 2001;358:870-5.

2. Taggart DP. The radial artery as a conduit for coronary artery bypass grafting. Heart. 1999;82:409-10.

3. Abu-Omar Y, Mussa S, Anastasiadis K, Steel S, Hands L, Taggart DP. Duplex ultrasonography predicts safety of radial artery harvest in the presence of an abnormal Allen test. Ann Thorac Surg. 2004;77:116-9.

4. Mussa S, Guzik TJ, Black E, Dipp MA, Channon KM, Taggart DP Comparative efficacies and durations of action of phenoxybenzamine, verapamil/nitroglycerin solution, and papaverine as topical antispasmodics for radial artery coronary bypass grafting. $J$ Thorac Cardiovasc Surg. 2003;126:1798-805.

5. He GW, Yang CQ. Use of verapamil and nitroglycerin solution in preparation of radial artery for coronary grafting. Ann Thorac Surg. 1996;61: 610-4.

6. Maniar HS, Sundt TM, Barner HB, Prasad SM, Peterson L, Absi T, et al. Effect of target stenosis and location on radial artery graft patency. J Thorac Cardiovasc Surg. 2002;123:45-52.

7. Possati G, Gaudino M, Prati F, Alessandrini F, Trani C, Glieca F, et al. Long-term results of the radial artery used for myocardial revascularization. Circulation. 2003;108:1350-4.

8. Buxton BF, Raman JS, Ruengsakulrach P, Gordon I, Rosalion A, Bellomo R, et al. Radial artery patency and clinical outcomes: fiveyear interim results of a randomized trial. J Thorac Cardiovasc Surg. 2003;125:1363-71.

9. Acar C, Ramsheyi A, Pagny JY, Jebara V, Barrier P, Fabiani JN, et al. The radial artery for coronary artery bypass grafting: clinical and angiographic results at five years. J Thorac Cardiovasc Surg. 1998; 116:981-9.

10. Possati G, Gaudino M, Alessandrini F, Luciani N, Glieca F, Trani C, et al. Midterm clinical and angiographic results of radial artery grafts used for myocardial revascularization. J Thorac Cardiovasc Surg. 1998;116:1015-21.

11. Iaco AL, Teodori G, Di Giammarco G, Mauro M, Storto L, Mazzei V, et al. Radial artery for myocardial revascularization: long-term clinical and angiographic results. Ann Thorac Surg. 2001;72:464-8; discussion $147-8$.

12. Tatoulis J, Royse AG, Buxton BF, Fuller JA, Skillington PD, Goldblatt JC, et al. The radial artery in coronary surgery: a 5-year experienceclinical and angiographic results. Ann Thorac Surg. 2002;143:143-7; discussion 147-8.

13. Khot UN, Friedman DT, Pettersson G, Smedira NG, Li J, Ellis SG. Radial artery bypass grafts have an increased occurrence of angiographically severe stenosis and occlusion compared with left internal mammary arteries and saphenous vein grafts. Circulation. 2004;109: 2086-91. 


\section{References}

1. Endo M, Nishida H, Tomizawa Y, Kasanuki H. Benefit of bilateral over single internal mammary artery grafts for multiple coronary artery bypass grafting. Circulation. 2001;104:2164-70.

2. Dion R, Glineur D, Derouck D, Verhelst R, Noirhomme P, El Khoury $\mathrm{G}$, et al. Long-term clinical and angiographic follow-up of sequential internal thoracic artery grafting. Eur J Cardiothorac Surg. 2000;17: 407-14.

3. Lytle BW, Blackstone EH, Loop FD, Houghtaling PL, Arnold JH, Akhrass R, et al. Two internal thoracic artery grafts are better than one. J Thorac Cardiovasc Surg. 1999;117:855-72.

4. Taggart DP, D'Amico R, Altman DG. Effect of arterial revascularisation on survival: a systematic review of studies comparing bilateral and single internal mammary arteries. Lancet. 2001;358:870-5.

5. Taggart DP. The radial artery as a conduit for coronary artery bypass grafting. Heart. 1999;82:409-10.

6. Cable DG, Mullany CJ, Schaff HV. The Allen test. Ann Thorac Surg. 1999;67:876-7.

7. Abu-Omar Y, Mussa S, Anastasiadis K, Steel S, Hands L, Taggart DP, et al. Duplex ultrasonography predicts safety of radial artery harvest in the presence of an abnormal Allen test. Ann Thorac Surg. 2004;77: 116-9.

8. Johnson WH 3rd, Cromartie RS 3rd, Arrants JE, Wuamett JD, Holt JB. Simplified method for candidate selection for radial artery harvesting. Ann Thorac Surg. 1998;65:1167.

9. Dorlas JC, Nijboer JA. Photo-electric plethysmography as a monitoring device in anaesthesia. Application and interpretation. $\mathrm{Br} J \mathrm{An}$ aesth. 1985;57:524-30.

10. Jarvis MA, Jarvis CL, Jones PR, Spyt TJ. Reliability of Allen's test in selection of patients for radial artery harvest. Ann Thorac Surg. 2000;70:1362-5.

11. Amano A, Takahashi A, Hirose H. Skeletonized radial artery grafting: improved angiographic results. Ann Thorac Surg. 2002;73:1880-7.

12. Rukosujew A, Reichelt R, Fabricius AM, Drees G, Tjan TD, Rothenburger M, et al. Skeletonization versus pedicle preparation of the radial artery with and without the ultrasonic scalpel. Ann Thorac Surg. 2004;77:120-5.

13. Ronan JW, Perry LA, Barner HB, Sundt TM 3rd. Radial artery harvest: comparison of ultrasonic dissection with standard technique. Ann Thorac Surg. 2000;69:113-4.

14. Cikirikcioglu M, Yasa M, Kerry Z, Posacioglu H, Boga M, Yagdi T, et al. The effects of the Harmonic Scalpel on the vasoreactivity and endothelial integrity of the radial artery: a comparison of two different techniques. J Thorac Cardiovasc Surg. 2001;122:624-6.

15. Casula RP, Kumar P, Ashrafian H, Athanasiou T. Evolving techniques for endoscopic radial artery harvesting. Cardiovasc Surg. 2003;11: 425-7.

16. Tatoulis J, Buxton BF, Fuller JA. Bilateral radial artery grafts in coronary reconstruction: technique and early results in 261 patients. Ann Thorac Surg. 1998;66:714-20.

17. Connolly MW, Torrillo LD, Stauder MJ, Patel NU, McCabe JC, Loulmet DF, et al. Endoscopic radial artery harvesting: results of first 300 patients. Ann Thorac Surg. 2002;74:502-6.

18. Cable DG, Caccitolo JA, Pearson PJ, O'Brien T, Mullany CJ, Daly $\mathrm{RC}$, et al. New approaches to prevention and treatment of radial artery graft vasospasm. Circulation. 1998;98(19 Suppl):II15-22.

19. Shapira OM, Alkon JD, Macron DS, Keaney JF Jr, Vita JA, Aldea GS, et al. Nitroglycerin is preferable to diltiazem for prevention of coronary bypass conduit spasm. Ann Thorac Surg. 2000;70:883-9.

20. Levy JH, Bailey JM, Deeb GM. Intravenous milrinone in cardiac surgery. Ann Thorac Surg. 2002;73:325-30.

21. Mussa S, Guzik TJ, Black E, Dipp MA, Channon KM, Taggart DP, et al. Comparative efficacies and durations of action of phenoxybenzamine, verapamil/nitroglycerin solution, and papaverine as topical antispasmodics for radial artery coronary bypass grafting. $J$ Thorac Cardiovasc Surg. 2003;126:1798-805.

22. Dipp MA, Nye PC, Taggart DP. Phenoxybenzamine is more effective and less harmful than papaverine in the prevention of radial artery vasospasm. Eur J Cardiothorac Surg. 2001;19:482-6.

23. He GW. Verapamil plus nitroglycerin solution maximally preserves endothelial function of the radial artery: comparison with papaverine solution. J Thorac Cardiovasc Surg. 1998;115:1321-7.

24. He GW, Yang CQ. Vasorelaxant effect of phosphodiesterase-inhibitor milrinone in the human radial artery used as coronary bypass graft. J Thorac Cardiovasc Surg. 2000;119:1039-45.
25. Garcia-Rinaldi R, Soltero ER, Carballido J, Mojica J. Intraluminal milrinone for dilation of the radial artery graft. Tex Heart Inst J. 1999;26:189-91.

26. He GW, Yang CQ. Use of verapamil and nitroglycerin solution in preparation of radial artery for coronary grafting. Ann Thorac Surg. 1996;61:610-4.

27. Taggart DP, Dipp M, Mussa S, Nye PC. Phenoxybenzamine prevents spasm in radial artery conduits for coronary artery bypass grafting. J Thorac Cardiovasc Surg. 2000;120:815-7.

28. Harrison WE, Mellor AJ, Clark J, Singer DR. Vasodilator pre-treatment of human radial arteries; comparison of effects of phenoxybenzamine vs papaverine on norepinephrine-induced contraction in vitro. Eur Heart J. 2001;22:2209-16.

29. Gaudino M, Glieca F, Luciani N, Alessandrini F, Possati G. Clinical and angiographic effects of chronic calcium channel blocker therapy continued beyond first postoperative year in patients with radial artery grafts: results of a prospective randomized investigation. Circulation. 2001;104(12 Suppl 1):I64-7.

30. Moran SV, Baeza R, Guarda E, Zalaquett R, Irarrazaval MJ, Marchant E, et al. Predictors of radial artery patency for coronary bypass operations. Ann Thorac Surg. 2001;72:1552-6.

31. Effect of target stenosis and location on radial artery graft patency, et al. Effect of target stenosis and location on radial artery graft patency. J Thorac Cardiovasc Surg. 2002;123:45-52.

32. Possati G, Gaudino M, Prati F, Alessandrini F, Trani C, Glieca F, et al. Long-term results of the radial artery used for myocardial revascularization. Circulation. 2003;108:1350-4.

33. Maniar HS, Barner HB, Bailey MS, Prasad SM, Moon MR, Pasque MK, et al. Radial artery patency: are aortocoronary conduits superior to composite grafting? Ann Thorac Surg. 2003;76:1498-504.

34. Sundt TM 3rd, Barner HB, Camillo CJ, Gay WA Jr. Total arterial revascularization with an internal thoracic artery and radial artery $\mathrm{T}$ graft. Ann Thorac Surg. 1999;68:399-405.

35. Calafiore AM, Di Giammarco G, Teodori G, D'Annunzio E, Vitolla G, Fino C, et al. Radial artery and inferior epigastric artery in composite grafts: improved midterm angiographic results. Ann Thorac Surg. 1995;60:517-24.

36. Possati G, Gaudino M, Alessandrini F, Luciani N, Glieca F, Trani C, et al. Midterm clinical and angiographic results of radial artery grafts used for myocardial revascularization. J Thorac Cardiovasc Surg. 1998;116:1015-21.

37. Tatoulis J, Royse AG, Buxton BF, Fuller JA, Skillington PD, Goldblatt JC, et al. The radial artery in coronary surgery: a 5-year experience-clinical and angiographic results. Ann Thorac Surg. 2002;73: 143-8.

38. Iaco AL, Teodori G, Di Giammarco G, Di Mauro M, Storto L, Mazzei $\mathrm{V}$, et al. Radial artery for myocardial revascularization: long-term clinical and angiographic results. Ann Thorac Surg. 2001;72:464-9.

39. Acar C, Ramsheyi A, Pagny JY, Jebara V, Barrier P, Fabiani JN, et al. The radial artery for coronary artery bypass grafting: clinical and angiographic results at five years. J Thorac Cardiovasc Surg. 1998; 116:981-9.

40. Fitzgibbon GM, Kafka HP, Leach AJ, Keon WJ, Hooper GD, Burton JR. Coronary bypass graft fate and patient outcome: angiographic follow-up of 5,065 grafts related to survival and reoperation in 1,388 patients during 25 years. J Am Coll Cardiol. 1996;28:616-26.

41. Goldman S, Copeland J, Moritz T, Henderson W, Zadina K, Ovitt T, et al. Saphenous vein graft patency 1 year after coronary artery bypass surgery and effects of antiplatelet therapy. Results of a Veterans Administration Cooperative Study. Circulation. 1989;80:1190-7.

42. The effect of aggressive lowering of low-density lipoprotein cholesterol levels and low-dose anticoagulation on obstructive changes in saphenous-vein coronary-artery bypass grafts. The Post Coronary Artery Bypass Graft Trial Investigators. N Engl J Med. 1997;336:15362.

43. Khot UN, Friedman DT, Pettersson G, Smedira NG, Li J, Ellis SG. Radial artery bypass grafts have an increased occurrence of angiographically severe stenosis and occlusion compared with left internal mammary arteries and saphenous vein grafts. Circulation. 2004;109: 2086-91.

44. Fremes SE. Multicenter radial artery patency study (RAPS). Study design. Control Clin Trials. 2000;21:397-413.

45. Buxton BF, Raman JS, Ruengsakulrach P, Gordon I, Rosalion A, Bellomo R, et al. Radial artery patency and clinical outcomes: fiveyear interim results of a randomized trial. J Thorac Cardiovasc Surg. 2003; $125: 1363-71$ 